\title{
CREVASSE DEFORMATION AND EXAMPLES FROM ICE STREAM B, ANTARCTICA
}

\author{
By P.L. VornBerger* and I.M. Whillans
}

(Byrd Polar Research Center and Department of Geology and Mineralogy, The Ohio State University,

Columbus, Ohio 43210, U.S.A.)

ABstract. Crevasses, once formed, are subject to rotation and bending according to the velocity field through which they travel. Because of this, crevasse shapes can be used to infer something about the velocity field of a glacier. This is done using a model in which each crevasse opens perpendicularly to the principal extensional strain-rate, when that strain-rate exceeds some specified critical value, and is then deformed according to the same velocity gradients that formed the crevasse. This model describes how crevasses are formed, translated, rotated, bent, and lengthened.

Velocity fields are sought for which calculations produce crevasses approximating those found in three example areas on Ice Stream B, Antarctica. The first example is the hook-shaped crevasses that occur just outside the chaotic shear zone at the ice-stream margin. They are used to infer a rate of lateral shearing, and side drag. The second example, a pattern of splaying crevasses, is satisfactorily simulated by a model with side-drag stress varying linearly across the ice stream. This confirms that this region is restrained almost entirely by side drag. The third example is transverse crevasses and their change in orientation, but many different velocity fields can produce the observed pattern. Of these three examples, the shapes of hook-shaped marginal crevasses and splaying crevasses can provide useful information whereas transverse crevasses are less helpful.

\section{INTRODUCTION}

Crevasses are prominent surface features on many glaciers, and they are caused by the deformation of the ice on which they develop. They form as open fractures in response to the stress field at the surface and are altered as they are carried down-glacier. If a theory for the formation and subsequent alteration of crevasses can be developed and proved, it may be possible to link the geometry of crevasses to the stress regime.

Much of this is done in an informal way by most field glaciologists. The presence of crevasses, itself, indicates larger stresses than elsewhere. Also, as Nye (1952) and Sharp (1960) have explained, the orientation of newly formed crevasses indicates the direction of principal stresses at the surface, and something of the surface-velocity field can be inferred from the manner in which crevasses are carried along and distorted after formation.

These principles have been applied to Ice Stream B, Antarctica (Fig. 1) (Vornberger and Whillans, 1986). Diagonally oriented crevasses have been used to infer the location of the margins of the ice stream where it shears past nearly stagnant ice. Other crevasses indicate that the ice flow is extensional for most of the length of the ice stream, until near the Ross Ice Shelf where lateral spreading dominates. Subsequent measurements of surface velocity of the ice stream (Bindschadler and others, 1986; Whillans and others, 1987) verify these deductions about the ice-flow

*Present address: ST Systems Corporation, 4400 Forbes Boulevard, Lanham, Maryland 20706, U.S.A. pattern. However, more information can be obtained from the crevasse field.

As a first step toward further development of this theory, we model the evolution of crevasses, and address three example crevasse patterns on Ice Stream B. The objective is to determine if crevasse shapes can be used to infer quantitative characteristics of the ice flow.

The development of the technique for the interpretation of crevasse patterns could be very valuable, especially with the current interest in the flow and stability of the polar ice sheets, and the advent of improved aerial photography and of satellite imagery. It may be possible to learn much about the dynamics of a glacier from remotely sensed crevasse patterns and a very limited field program.

\section{THE MODEL}

The development of a crevasse is followed through a specified, steady two-dimensional velocity field. Glaciers generally do not change flow patterns quickly, especially not over the time span during which a crevasse field forms. This means that a map of a train of crevasses is also a depiction of the evolution of a single crevasse in various phases of its development as it traverses the velocity field. Crevasse patterns thus may be taken to depend only on the velocity field and the criteria for the initial formation of crevasses.

This assumption of steadiness is somewhat at variance with Whillans and others (1987), who argued that the flow of Ice Stream B is non-homogeneous and non-steady. It is assumed here that the velocity field is steady on the 100 year time-scale needed for crevasse systems to develop. Also, the assumption of steady flow simplifies the problem.

In this model, crevasses are assumed to form when the principal extensional strain-rate exceeds a critical value. The critical strain-rate has been measured in earlier studies. It is about $0.01 \mathrm{a}^{-1}$ in temperate ice (Meier (1958) for Saskatchewan Glacier, Alberta, Canada; Meier and others (1957) for Blue Ice Valley, Greenland; Holdsworth (1965, 1969) for Kaskawulsh Glacier, Yukon Territory, Canada) and about $0.002 \mathrm{a}^{-1}$ in polar ice at $-28^{\circ} \mathrm{C}$ (Holdsworth (1969) at Meserve Glacier, Antarctica). The firn temperature on Ice Stream B at the UPB camp (Fig. 1) at $17.4 \mathrm{~m}$ depth varies between $-28^{\circ}$ and $-25^{\circ} \mathrm{C}$, so the critical strain-rate of $0.002 \mathrm{a}^{-1}$ obtained for Meserve Glacier is used.

The onset of crevassing requires further study, especially to determine if ice fabric, texture, or the rate of stress increase are important. Also, on crevasse formation, some of the stress in the upper layer of the glacier is relieved and so, in many examples, new crevasses do not form near existing crevasses. This process helps determine crevasse spacing, but, as is discusssed below, this spacing is irregular, which indicates that crevasse formation is more complex than these simple ideas would allow. There are thus a number of unresolved issues with regard to crevasse initiation. However, for the work here, we assume that crevasses form when a critical strain-rate is attained. The actual value of the critical strain-rate is not as important, for this study, as that there is some value and that 


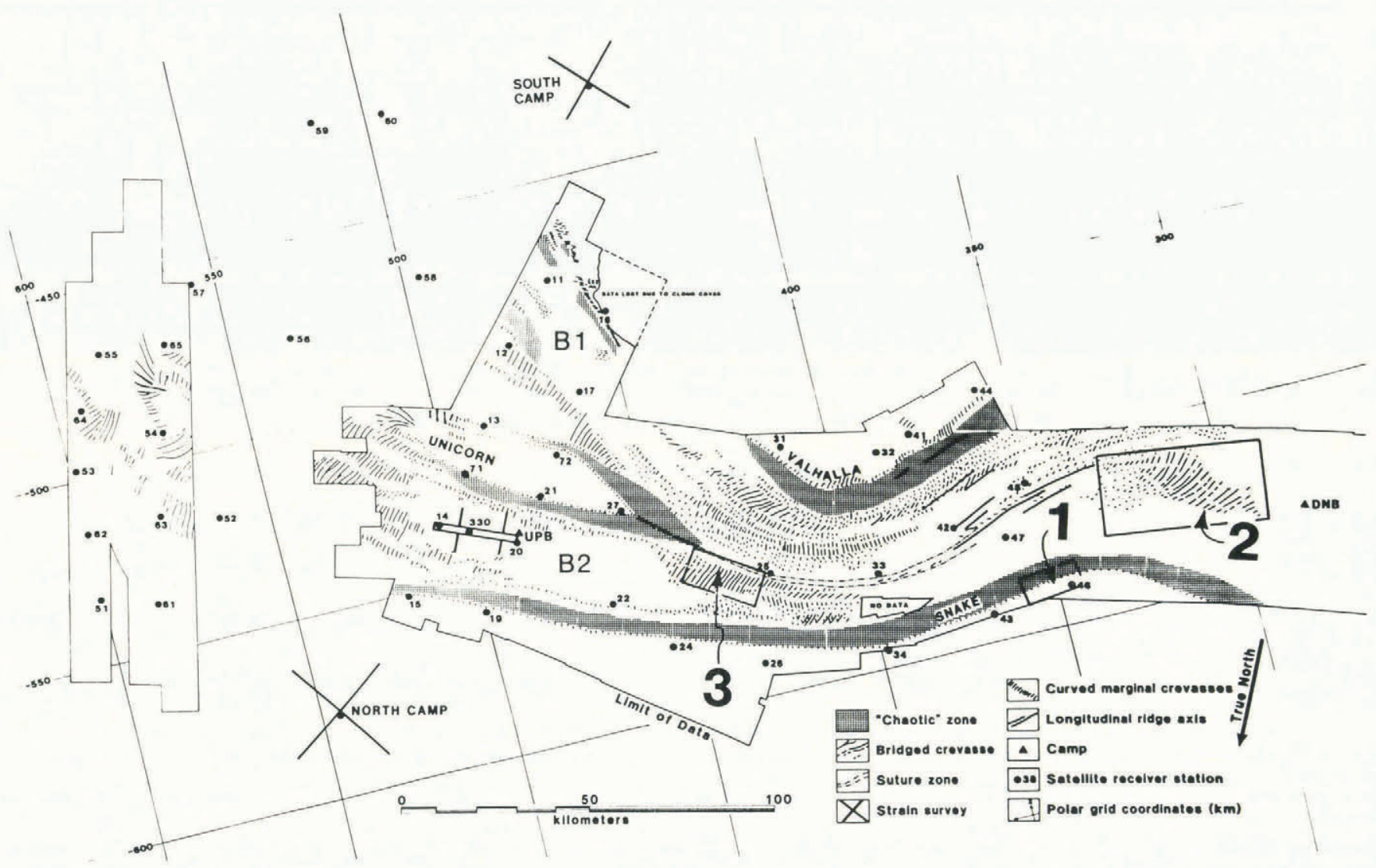

Fig. 1. Visible features on Ice Stream B, West Antarctica. True south is roughly towards the top of the map. Large numbers indicate the crevasse patterns modelled here $(1$, curved marginal crevasses; 2 , splaying crevasses; 3 , transverse crevasses). Approximately every twentieth crevasse is shown. Ice flow is left to right, and numbered dots are velocity-measurement stations. This map was prepared from a mosaic of aerial photographs. The coordinate system has been described in Whillans and others (1987).

crevasses form consistently according to this critical value.

Once the crevasse is formed, the trajectories of points along the crevasse are traced. Thus, at any time, the position and shape of the crevasse are described by a line connecting the points. If the crevasse lengthens, more points are included in the calculations.

Particle trajectories are found by solving equations describing velocity for position as a function of time. The velocity field is described by the components of the horizontal ice-surface velocity, $u_{x}=\mathrm{d} x / \mathrm{d} t$ and $u_{y}=\mathrm{d} y / \mathrm{d} t$ at horizontal position $(x, y)$. They are given by the firstorder terms in a Taylor series expansion about $(0,0)$ :

$$
\begin{aligned}
& u_{x}(x, y)=u_{x}(0,0)+\left(u_{x, x}\right) x+\left(u_{x, y}\right) y \\
& u_{y}(x, y)=u_{y}(0,0)+\left(u_{y, x}\right) x+\left(u_{y, y}\right) y
\end{aligned}
$$

where $u_{x}(0,0)$ and $u_{y}(0,0)$ are specified velocity components at the origin of the coordinate system, and $u_{x, x}, u_{x, y}, u_{y, x}$, and $u_{y} y$ are specified velocity gradients (Table $\mathrm{I}$ ).

Recalling that $u_{x}=\mathrm{d} x / \mathrm{d} t$ and $u_{y}=\mathrm{d} y / \mathrm{d} t$, and eliminating $x$, these equations are solved for $y$ as a function of time together with two boundary conditions:

1. Initial position (at $t=0$ ):

$$
y=y_{0} \text {; and }
$$

2. Initial velocity (at $t=0$ ):

$$
\mathrm{d} y / \mathrm{d} t=u_{y}(0,0)+u_{y, x^{x_{0}}}+u_{y, y y_{0}}
$$

where $\left(x_{0}, y_{0}\right)$ is the starting position of the selected trajectory. Similar conditions are used in solving for $x$.

The Appendix contains a fuller explanation of how the equations are solved. Analytic expressions are obtained for $x$
TABLE I. DEFINITIONS OF VELOCITY GRADIENTS ( $x$ is directed along the flow direction of the ice stream, and $y$ across flow)

$$
\begin{aligned}
& u_{x, x}=\frac{\partial u_{x}}{\partial x}: \text { longitudinal stretching } \\
& u_{x, y}=\frac{\partial u_{x}}{\partial y}: \text { side shearing } \\
& u_{y, y}=\frac{\partial u_{y}}{\partial y}: \begin{array}{l}
\text { lateral extension or spreading or, } \\
\text { if negative, compression }
\end{array} \\
& u_{y, x}=\frac{\partial u_{y}}{\partial x}: \text { flow-line turning }
\end{aligned}
$$

and $y$ as a function of time, $t$, start position $\left(x_{0}, y_{0}\right)$, and velocity gradients $\left(u_{x, x}, u_{x, y}, u_{y, x}\right.$, and $\left.u_{y, y}\right)$.

\section{EXAMPLE OF MARGINAL CREVASSES}

The outermost component of Ice Stream B is a train of curved crevasses abutting against an inter-stream ridge (Figs 1 and 2). The length of these curved crevasses is relatively constant, and they are concave down-glacier. Each crevasse is straight at its end nearest the inter-stream ridge, and becomes hook-shaped at its other end, next to the chaotic zone. The chaotic zone is a region of intersecting crevasses and snowdrifts and is believed to be composed of ice that has flowed from the inter-stream ridge into the ice stream. The shape, length, and spacing of the curved marginal crevasses are similar along all the margins of Ice Stream B, with an exception only at the bend in the southern margin 


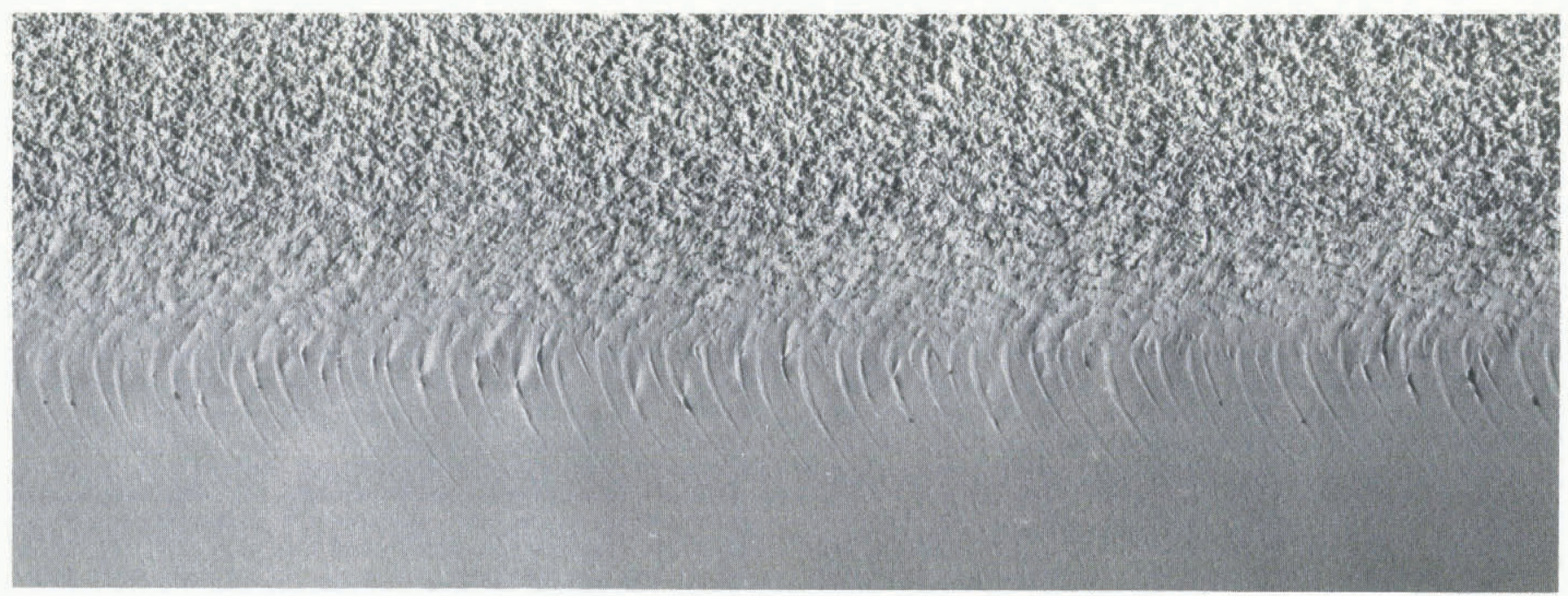

Fig. 2. Part of an aerial photograph, showing a $4.3 \mathrm{~km}$ by $1.6 \mathrm{~km}$ part of the ice-stream margin near " $I$ " in Figure 1. The complex region is the chaotic zone of the ice stream, which is moving left to right. The long curved crevasses are studied here. The smooth region is part of the inter-stream ridge which is flowing slowly towards the ice stream. (U.S.G.S. flight TMA-2517-V, exposure number 12-132, lat. $83^{\circ} 45^{\prime} \mathrm{S}$., long. $148^{\circ} \mathrm{W}$., near station 43 ).

("Valhalla" in Figure 1), where they are longer and more smoothly curved.

To simulate crevasses in the ice-stream margin, two zones are defined (Fig. 3). The first is part of the interstream ridge, where the principal extensional strain-rate is not sufficient to form crevasses. Ice flows into the second zone, where the principal extensional strain-rate is large enough to form crevasses. In the model, the boundary between the two zones, the crevasse-initiation line, is straight and its position is fixed. As the ice is carried away from the crevasse-initiation line, the crevasse continues to grow and extend back to the line. The older part of the crevasse is carried down-glacier and rotated because of the simple shear. The resulting hook-shaped crevasses are like those observed in Nature.

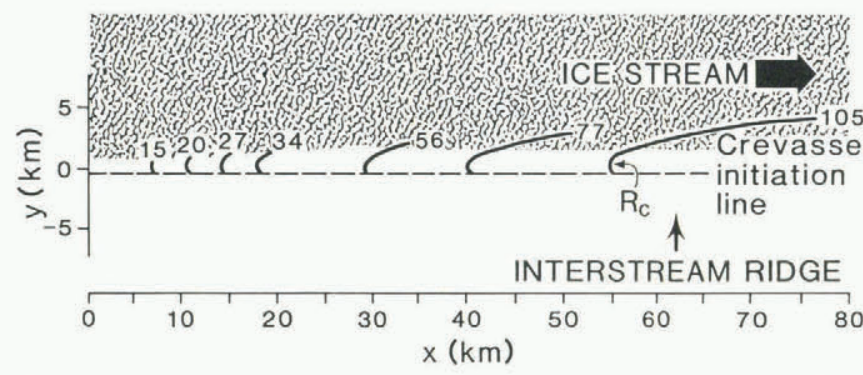

Fig. 3. Formation of a curved marginal crevasse by flow from the inter-stream ridge $\left(u_{y}=50 \mathrm{ma}^{-1}\right)$ and side shear $\left(u_{x, y}=0.09 a^{-1}\right)$. Straight arrows indicate ice-flow direction. Along the crevasse-initiation line, $u_{x}=0$. Crevasse ages in years are shown next to the crevasses. The calculations begin at the origin.

A useful measure is the radius of curvature at the tightest bend in the crevasses, $R_{\mathrm{C}}$. It is measured by matching circular arcs in an overlay with crevasses on the photographs. The point of sharpest curvature is at the end of the crevasse nearest the chaotic zone. The major uncertainty in measuring $R_{\mathrm{c}}$ arises because one side of the crevasse is difficult to trace into the chaotic zone. In some cases, so much of the crevasse has been incorporated into the chaotic zone that an accurate curvature cannot be obtained. Nevertheless, where obtainable, the value of $R_{\mathrm{c}}$ is fairly consistent from crevasse to crevasse with an average value of $250 \mathrm{~m}( \pm 150 \mathrm{~m})$. Only at "Valhalla" is the value of $R_{\mathrm{c}}$ different, being $3500 \mathrm{~m}$. In this study, the more typical crevasses at straight margins are studied.

There are also some short $(50-300 \mathrm{~m}$ long) straigh crevasses between the curved marginal crevasses (Fig. 2). These crevasses have the same orientation as the outermost straight part of the curved marginal crevasses, and they occur directly against the chaotic zone. This similarity in orientation of the short straight crevasses and the younger straight part of the curved crevasses supports the assumption that the direction of principal extensional strain-rate in this area is constant.

Figure 3 shows the development of one crevasse. The rotation rate of the crevasse first increases and then decreases, and for this example, with rather large values of $u_{y}$ and $u_{x, y}$, the sharpest curvature is attained after about $15 \mathrm{~km}$ of transport.

The two major influences on crevasse shape are side shear (such terms are defined in Table I) and the rate at which ridge ice is flowing into the ice stream $\left(u_{v}\right)$. From the model runs, these quantities are found empirically to be linked to the minimum radius of curvature by

$$
R_{\mathrm{c}}=2\left|u_{y} / u_{x, y}\right|, \quad \text { for } u_{y, y}=0 .
$$

Figure 4 shows this line. The crevasse shape, expressed by

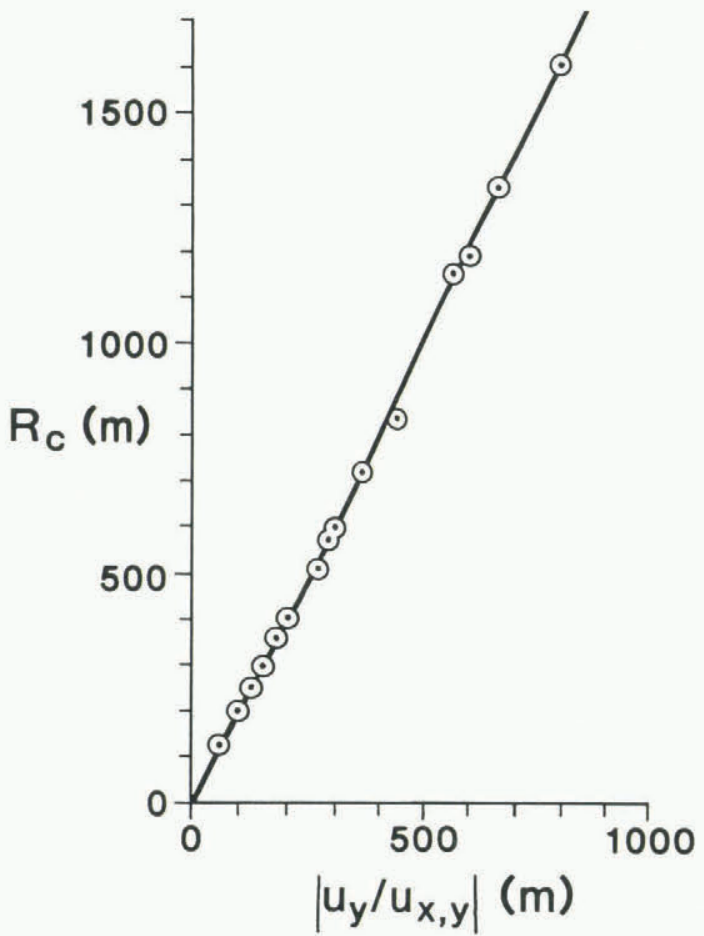

Fig. 4. The radius of curvature, $R_{c}$, is linearly related to $\left|u_{y} / u_{x y}\right|$. for the case of $u_{x x}=0=u_{y y}$. The points show the results of numerical calculations for values of $\left|u_{y}\right|$ ranging from 5 to $40 \mathrm{ma}^{-1}$, and $\left|u_{x, y}\right|$ ranging from 0.01 to $0.15 \mathrm{a}^{-1}$. The scatter about the line is due to the numerical approximations involved in calculating $R_{C}$ 
$R_{\mathrm{c}}$, is simply related to the ratio of flow rate from the inter-stream ridge, $u_{y}$, to rotation rate, $u_{x, y} / 2$.

Lateral extension $\left(u_{y}>0\right)$ or compression $\left(u_{y,}<0\right)$ also affects the radius of curvature because it changes the value of $u_{y}$ along the length of the crevasse. For a given value of $u_{y}$ at the crevasse-initiation line, lateral compression causes the value of $u_{y}$ to be less as distance from the crevasse-initiation line increases (Fig. 5). This means that $u_{y}$ at the point of maximum curvature is smaller, and, by the equation above, this leads to a more tightly curved crevasse. Lateral compression also tends to bring the tips of the crevasse closer together. The result of both processes is a smaller radius of curvature. Conversely, lateral extension causes the crevasse to be stretched out and the radius of curvature to be larger.

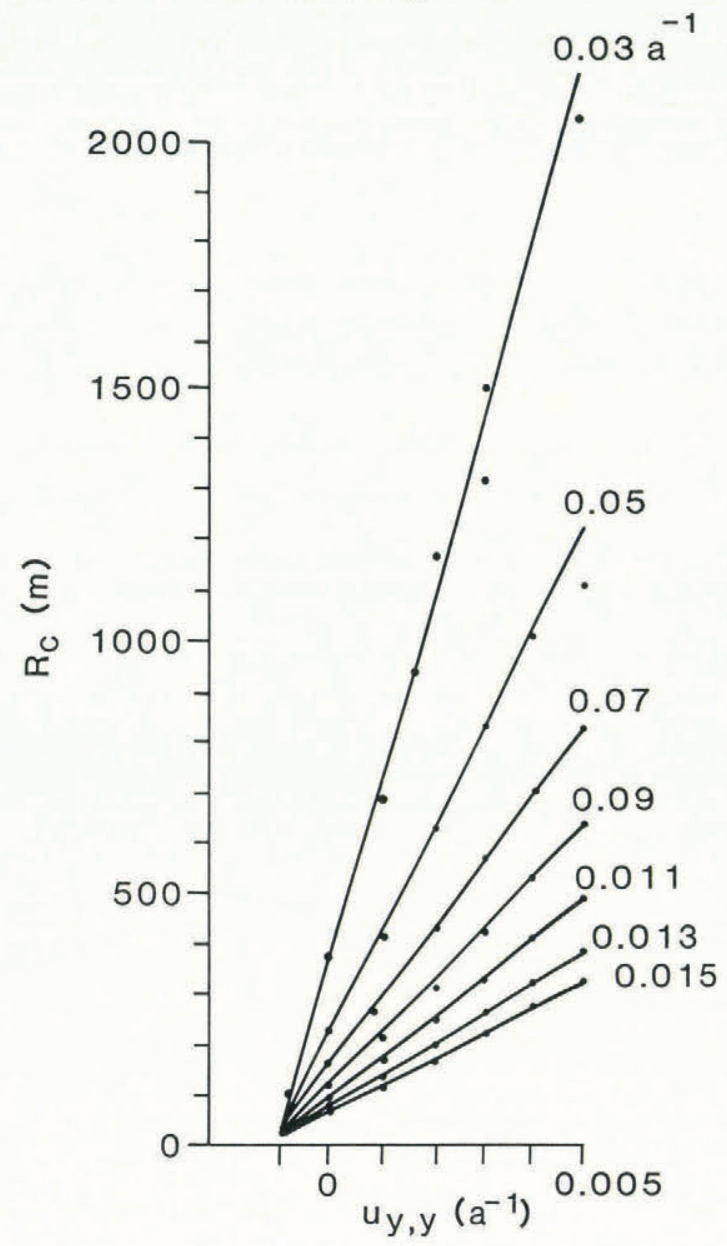

Fig. 5. Radius of curvature, $R_{c}$, versus lateral velocity gradient, $u_{y}$, for a lateral flow rate $u_{y}=6 \mathrm{ma}^{-1}$. Each line is for the rate of side shear, $u_{x, y}$, indicated. The lines are obtained by fits to the results of numerical calculations (dots).

Longitudinal stretching $\left(u_{x}\right)$ is not considered in this model, because, in this model, the ice flow is directly across the crevasse-initiation line into the ice stream, so $u_{x}=0$ at all $x$ along that line.

The fourth velocity gradient, $u_{y, x}$, is also not included here. This gradient causes flow-line turning, and thus would make the crevasse-initiation line curved. It would be applicable to the crevasses near "Valhalla", but that is not attempted here.

Measurements of the radius of curvature of marginal crevasses along the northern margin of Ice Stream B, or "Snake", are now used to infer a value for side shear at the margin. The radius of curvature for marginal crevasses along the "Snake" is $250 \pm 150 \mathrm{~m}$. Velocity measurements for stations $15,19,24,26,34$, and 46 on the ice ridge indicate a flow rate from the inter-stream ridge, $u_{y}$, of about $6 \mathrm{~m} \mathrm{a}^{-1}$ (Whillans and others, 1987). This value is also that needed to balance snow accumulation on the inter-stream ridge. Substituting that rate into Equation (5), one obtains $u_{x, y}=0.048 \mathrm{a}^{-1}$, with a range of $0.03-0.12 \mathrm{a}^{-1}$. This rate of side shear agrees closely with the value of about $0.05 \mathrm{a}^{-1}$ measured in the "Snake" at the longitude of DNB camp (Bindschadler and others, 1987a).

In this calculation, the rate of lateral spreading, $u_{y, y}$ is set to zero. In fact, the flow pattern shows small laterally compressive values in the upper and central parts of Ice Stream B and small extensive values near the ice shelf. These effects could be included but this is not warranted considering the difficulty in obtaining precise curvatures. The effect would be small.

The curved marginal crevasses are thus useful for estimating the value of side-shear rate, $u_{x, y}$, at the icestream margin. The major limitation arises because the older ends of the crevasses are in the chaotic zone where they cannot be traced. This causes an uncertainty in the measured value of crevasse curvature. The method leads to a determination of the side-shear rate to within a factor of about 4. This is a valuable method for obtaining rough estimates of this velocity gradient. Through use of a flow law, one can then compute lateral drag. In this case, it is about $200 \mathrm{kPa}$ (using a rate factor of $700 \mathrm{kPa} \mathrm{a}^{-1 / 3}$ from Hooke (1981)). The technique is most appropriate to use for valley glaciers and ice streams for which there are no direct measurements.

\section{EXAMPLE OF SPLAYING CREVASSES}

Splaying crevasses occur in the region near DNB camp (Figs 1 and 6), and Figure 7 is a schema of the general pattern. In valley glaciers, this pattern typically results from lateral extension and side shear (Sharp, 1960). On Ice Stream B they also occur in an area of lateral extension, and only one side of the full pattern is visible.

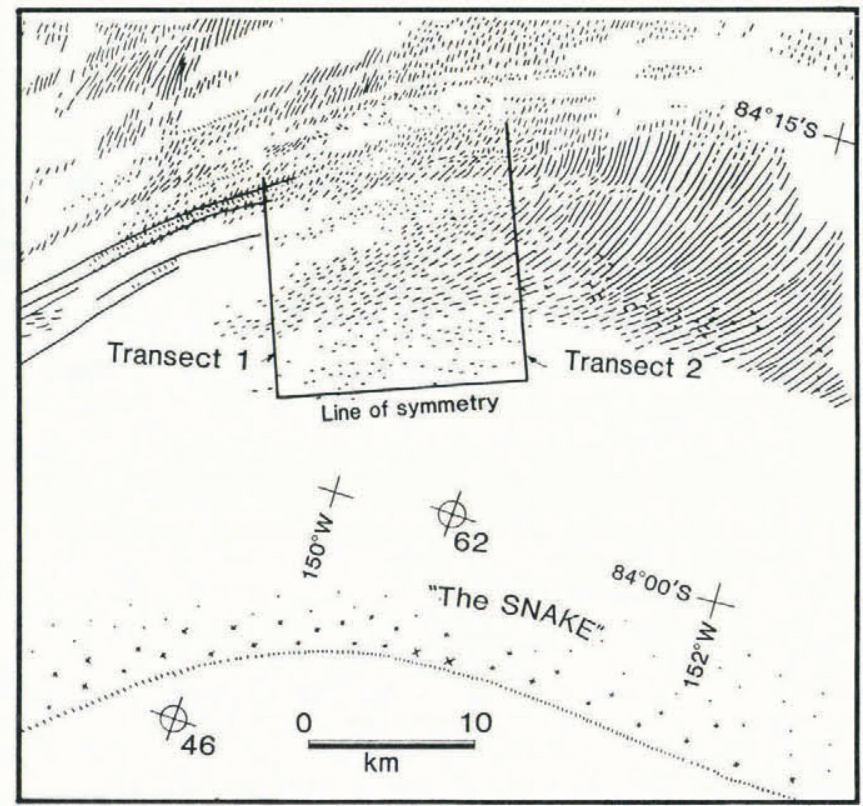

Fig. 6. Map of the splaying crevasse pattern ("2" in Figure 1). Ice flow is left to right. Numbered circles are velocity stations. Number 46 is also indicated in Figure 1. Transects 1 and 2 and the line of symmetry are discussed in the text.

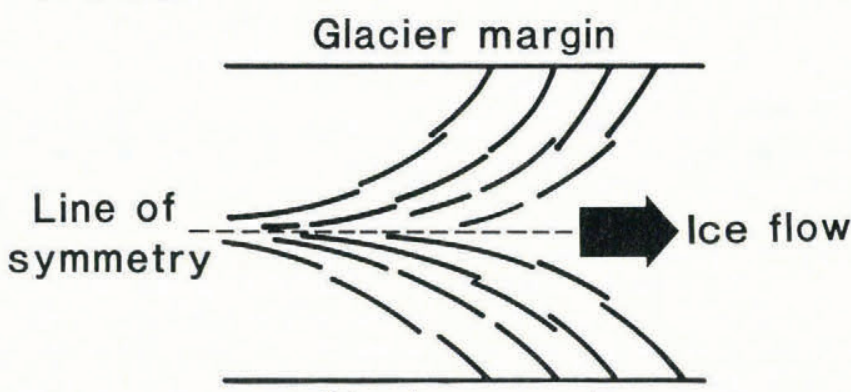

\section{Glacier margin}

Fig. 7. Typical splaying crevasses on a valley glacier. Due to lateral extension, crevasses are longitudinally oriented at the line of symmetry. At the glacier sides, side shear results in crevasses at $45^{\circ}$. (Taken from Sharp, 1960 , p. 52.) 
Following experience on valley glaciers, this crevasse pattern is taken to be due to a combination of lateral extension and side shear. This therefore involves the velocity gradients $u_{y, y}$ and $u_{x, y}$ (Table I). The spatially averaged lateral extension rate is uniform throughout this region, except for very local variations (Bindschadler and others, 1987a). These authors also inferred that the side-shear stress varies across the ice stream, being more important at the margin than at the center. There is thus both lateral extension and a gradient of side shear across the glacier.

To model this situation, adjacent linear velocity fields are connected. This is necessary because side shearing is not constant and the trajectory calculations are for constant velocity gradients. Separate linear-velocity fields or "panels" are arranged side by side as shown in Figure 8. As applied here, the value of extension $\left(u_{y, y}\right)$ is the same for all

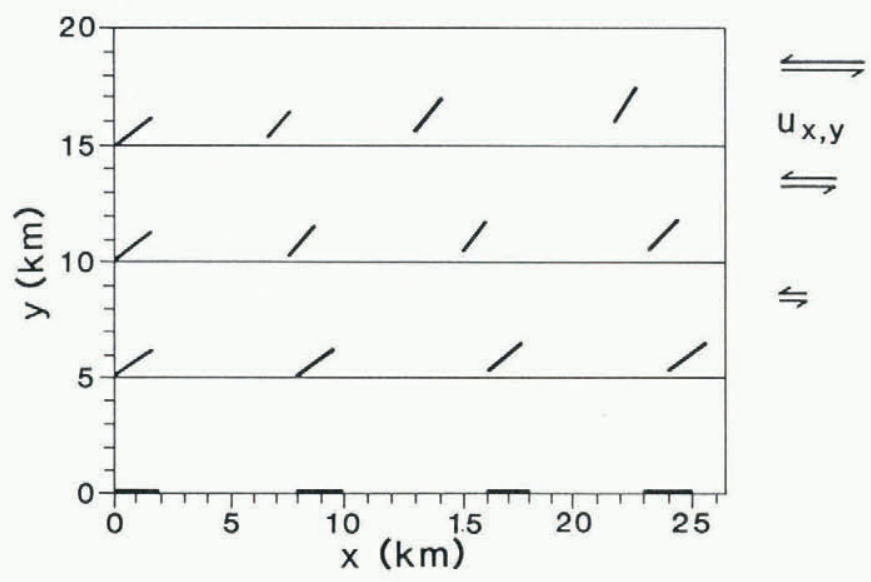

Fig. 8. Crevasse position with distance for adjacent rectangular velocity fields. Four are shown, but eight are used in the calculations. Ice flow is left to right. Side shearing, $u_{x, y}$ changes linearly from zero at the line of symmetry $(y=0)$. The crevasses first form at $x=0$.

velocity fields, but this is not necessary. The side shear $\left(u_{x, y}\right)$ is zero at the line of symmetry of the crevasse pattern, increases from one panel to the next, and is $0.05 \mathrm{a}^{-1}$ at the margin. This incorporates the second derivative, $u_{x, y y}$ (also written $\partial^{2} u_{x} / \partial y^{2}$ ). Crevasse orientations in each panel are calculated separately.

The first experiment is for a constant value of $u_{x, y y}$. Crevasse orientations are calculated using lateral extension $u_{y, y}=0.002 \mathrm{a}^{-1}$, and with side shear, $u_{x, y}$ increasing linearly $\left(u_{x, y y}=0.002 \mathrm{a}^{-1} \mathrm{~km}^{-1}\right)$ along the $y$-direction (Fig. 8). However, the orientations of modelled (Fig. 8) and observed (Fig. 6) crevasses agree only for those crevasses along, and farthest from the line of symmetry. In the intermediate panels, at 7.5 and $12.5 \mathrm{~km}$ from the line of symmetry, the modelled crevasses are turned more than those observed.

This result indicates that $u_{x, y y}$ is not constant. The simplest model for tranverse variations in $u_{x}$ is that of lamellar flow, in which side-shear stress varies linearly across the ice stream and there are no other stresses (e.g. Whillans and others, 1987). Lamellar flow produces lateral shearing that varies as the $n$th power of distance, $y$, from the line of symmetry,

$$
u_{x, y}=c y^{n}
$$

where $n$ is the exponent in Glen's flow law and $c$ is a constant. Whillans and others also calculated shearing in the presence of additional normal stresses, and that leads to an additional linear term on the right-hand side of Equation (6). Here, however, only the simpler, lamellar case described by Equation (6) is considered.

The value of $c$ is found from the orientation of crevasses in their nascent zone. This is at transect 1 (Fig. 6) at the up-glacier end of the crevasse field near where they first form. Considering that crevasses form perpendicular to the orientation of principal extension, the orientation of a new crevasse is obtained from elementary principles and is

$$
\theta=\frac{1}{2} \tan ^{-1}\left[\left(u_{x, y}+u_{y, x}\right) /\left(u_{x, x}-u_{y, y}\right)\right]
$$

where $\theta$ is measured anticlockwise from the line of symmetry in Figure 6 . The gradients $u_{x, x}=-0.001 \mathrm{a}^{-1}, u_{y, y}$ $=0.002 \mathrm{a}^{-1}$, and $u_{y, x}=0$ are available from field measurements (Bindschadler and others, 1987b). The value of $u_{x}$ obtained by re-arranging Equation (7), is shown in Figure 9. Only data to a distance of $9 \mathrm{~km}$ are shown. Crevasses

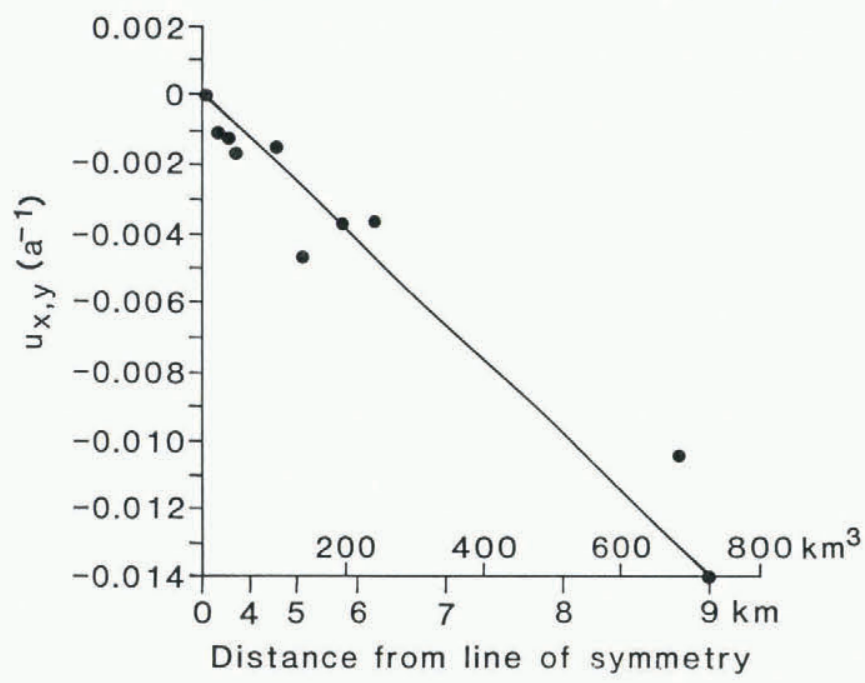

Fig. 9. Side shear versus distance from the line of symmetry, cubed, in the nascent area (transect 1). Data are from measurements of $\theta$ on Figure 6 and the solution of Equation (7) for $u_{x, y}$.

beyond that distance are oriented with $\theta>45^{\circ}$, which is inconsistent with our model. Presumably, the true nascent zone for these crevasses is farther up-glacier. Crevasses up-glacier of transect 1 are not visible in the photographs, but they could be present and be small enough to be bridged with snow. A further difficulty is that the angle $\theta$ is difficult to estimate because the crevasses are not entirely regular in orientation. The uncertainty in $u_{x}$ in Figure 9 increases with distance, $y$, and reaches $0.002 \mathrm{a}^{-1}$. Ignoring these complications, the plot indicates that the data can be represented by the usual value of $n=3$. The value of $c$ is provided by the slope of this line $\left(c=-2 \times 10^{-5} \mathrm{a}^{-1} \mathrm{~km}^{-3}\right)$.

Somewhat different exponents in Equation (6) or inclusion of other stresses, or a more complex lateral variation in side-shear stress, could also be consistent with observation. However, the case of $n=3$ and Equation (6) is simple and is a good first model for the crevasse pattern in the nascent area.

A further test of the model is provided by considering the translation and rotation of crevasses from transect 1 to transect 2. The crevasses, once formed, are carried with the ice flow and are rotated because the center of the ice stream moves faster than nearer the margins. These effects are shown in Figure 10. For reference, the corresponding orientations for transect 1 , as used in Figure 9, are also plotted. Some agreement is obtained between model and observation for crevasses far from the line of symmetry.

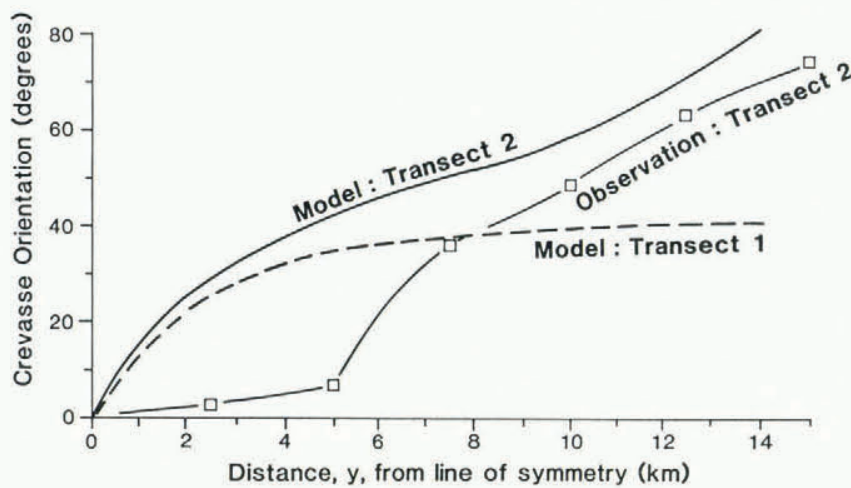

Fig. 10. Crevasse orientation as a function of distance from the line of symmetry. The transects are shown in Figure 6. Transect $l$ is near the nascent area for the crevasses and the solid curve represents values calculated using Equation (7). Transect 2 is $14 \mathrm{~km}$ farther down-glacier. 
Deficiencies in the match between model and observation occur in the first few kilometers from the line of symmetry. This could be repaired simply by redefining the position of that line of symmetry. About $5 \mathrm{~km}$ farther south would be suitable and still be consistent with the crevasse pattern (Fig. 6).

An important assumption in the model is that side drag varies linearly across the ice stream. This assumption is valid if there are no major variations in basal drag, ice thickness, or surface slope in the area. A suitable case is where the ice is afloat.

This seems to be the situation here. Bindschadler and others (1987a) conducted a force-budget study and found that basal drag is near zero. The bed must be welllubricated. Robin and others (1970) termed such a region "a pseudo-ice shelf". Bindschadler and others found that the driving stress, which is only $2.6 \mathrm{kPa}$, is mainly balanced by gradients in side drag. Back pressure from the ice shelf is unimportant. This is consistent with the model results here.

Bindschadler and others assumed that the region immediately down-glacier from the splaying pattern has near-zero side shear. This is inconsistent with the present results, that find very large side shearing, that reaches $0.014 \mathrm{a}^{-1}$ (Fig. 9). Including this finding in the force-budget analysis indicates that the resistance to flow is even more completely dominated by side drag than Bindschadler and others concluded.

Modelling the region of splaying crevasses as a pseudoice shelf and using the present crevasse model seems to work adequately. Other more complex interpretations have not been exhaustively explored. However, we believe that the existence of splaying crevasses is a useful indication that the flow regime is dominated by lateral spreading and maybe by a near-linear variation in side drag.

We have not attempted to model splaying crevasses on a valley glacier. Presumably, one could also learn about the lateral variation in basal drag from such a study.

\section{EXAMPLE OF TRANSVERSE CREVASSES}

The surface of most of Ice Stream B is dominated by transverse crevasses (Fig. 1). These form as a result of longitudinal extension. Their lengths are typically in the range $0.25-2.0 \mathrm{~km}$, and crevasses up to $10 \mathrm{~km}$ long are observed. As shown in Figures 1 and 11, these crevasses are commonly grouped in bands or trains. Each band contains crevasses of similar length and is separated from adjacent bands by narrow crevasse-free zones.

The cause of crevasse banding is not understood. Vornberger and Whillans (1986) speculated that each band of crevasses originates over a basal obstruction. The upglacier end of the band is at the obstruction, and as the ice is carried away, a new crevasse is formed and joins the band. Alternatively, the bands may be associated with rafts of inland ice that are carried by the ice stream (cf. Whillans and others, 1987). The precise cause of the banding is, however, not believed to be important to the crevasse model used here.

It was hoped that the change in the along-flow spacing of transverse crevasses could be used to indicate the longitudinal strain-rate of inter-crevasse blocks. However, as Meier (1958) found for a site in north-west Greenland, the spacing between successive crevasses is of ten very irregular. This may be caused by an unsteady process of crevasse formation, or by inhomogeneities in the ice. The irregularity in spacing in one part of a crevasse band can be greater than the average spacing along the band. For example, crevasse spacing along a flow line less than $10 \mathrm{~km}$ long can vary between 100 and $500 \mathrm{~m}$, where the average ice velocity is about $400 \mathrm{~m} \mathrm{a}^{-1}$. On Ice Stream B, the longitudinal stretching computed in this way varies between 0.004 and $0.040 \mathrm{a}^{-1}$, depending on the particular crevasses or groups of crevasses selected. This variation is much greater than the uncertainty due to measurement error. It seems unlikely that longitudinal strain-rates can vary so much and so meaningful values cannot be obtained from crevasse spacing on Ice Stream B.

Crevasse spacing is thus not helpful, but the shape and orientation of individual crevasses may indicate the values of certain other velocity gradients. Superimposing side shear, $u_{x, y}$, on longitudinal stretching, $u_{x, x}$, causes the crevasse to open at an orientation different from transverse stretching. More important to this application, it also causes the crevasse to change orientation as it is carried down-glacier because one end of the crevasse is carried faster than the other (Fig. 12, top). The rotation is uniform along the length of the crevasse, and so the crevasse remains straight as it is turned. We now investigate whether the progressive rotation of transverse crevasses can provide useful information.

The lower part of Figure 12 shows how the crevasse turning rate changes with distance down-glacier from its nascent area. The angle $\theta$ is measured with respect to a practical axis $X$, which is approximately along-flow. The initial turning rate is, from elementary principles,

$$
\partial \theta / \partial X(0,0)=-\frac{1}{2}\left(u_{x, y}-u_{y, x}\right) / u_{x}(0,0)
$$

where $u_{\chi}(0,0)$ is the value of $u_{X}$ at crevasse formation. Figure 12 shows results for the case of $u_{y, x}=0$.

The crevasse turning rate of ten increases with progressive translation and rotation of the crevasse. Basic principles and the model experiments show that it can reach a maximum of

$$
|\partial \theta / \partial X(\max )|=\text { larger of }\left[\left|u_{x, y}\right|,\left|u_{y, x}\right|\right] / u_{x}^{*}
$$

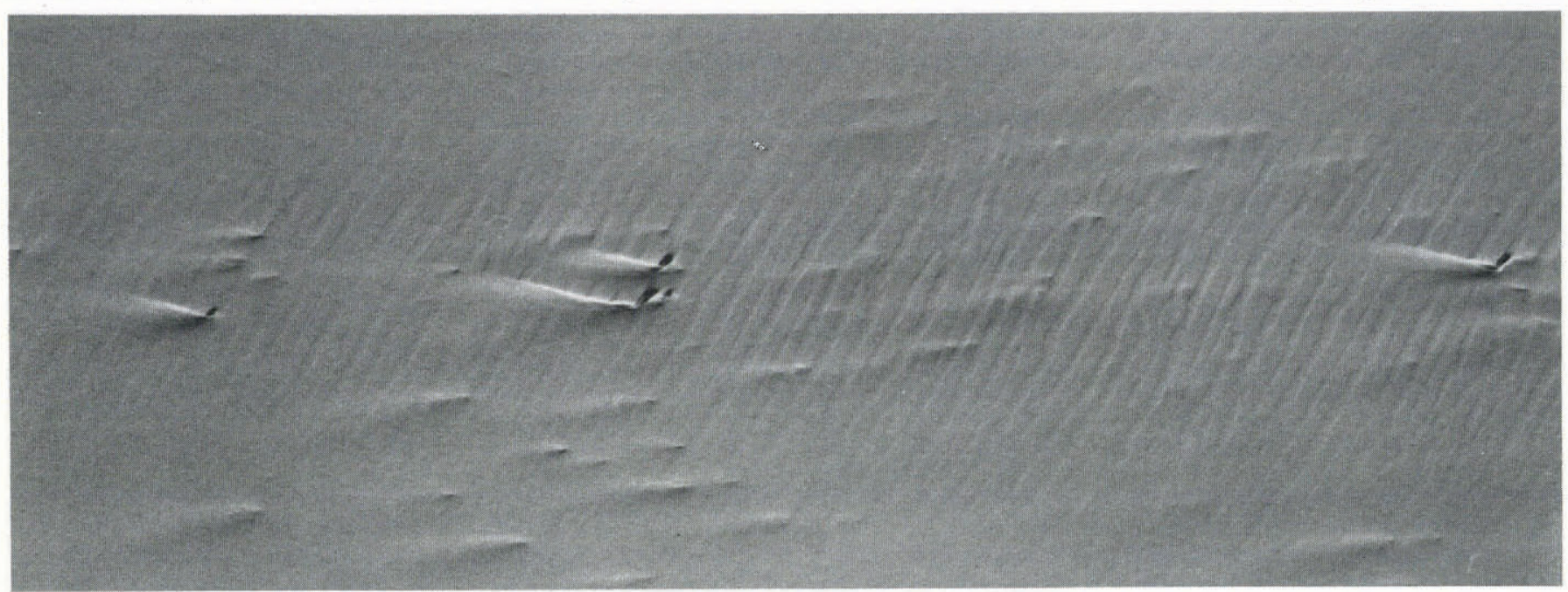

Fig. 11. Detail of the central part of Ice Stream B, showing part of one band of transverse crevasses (" 3 " in Figure 1). The flow and wind direction are right to left and illumination is from the top. Length depicted is $3.7 \mathrm{~km}$. Also evident are drift mounds, formed by the collection of snowdrift behind stationary wind eddies associated with collapsed crevasse bridges. Some drift mounds no longer have an associated open crevasse. (U.S.G.S. flight TMA-2509-V, exposure number 10-056, lat. $83^{\circ} 35^{\prime} S$., long. $143^{\circ} \mathrm{W}$.). 


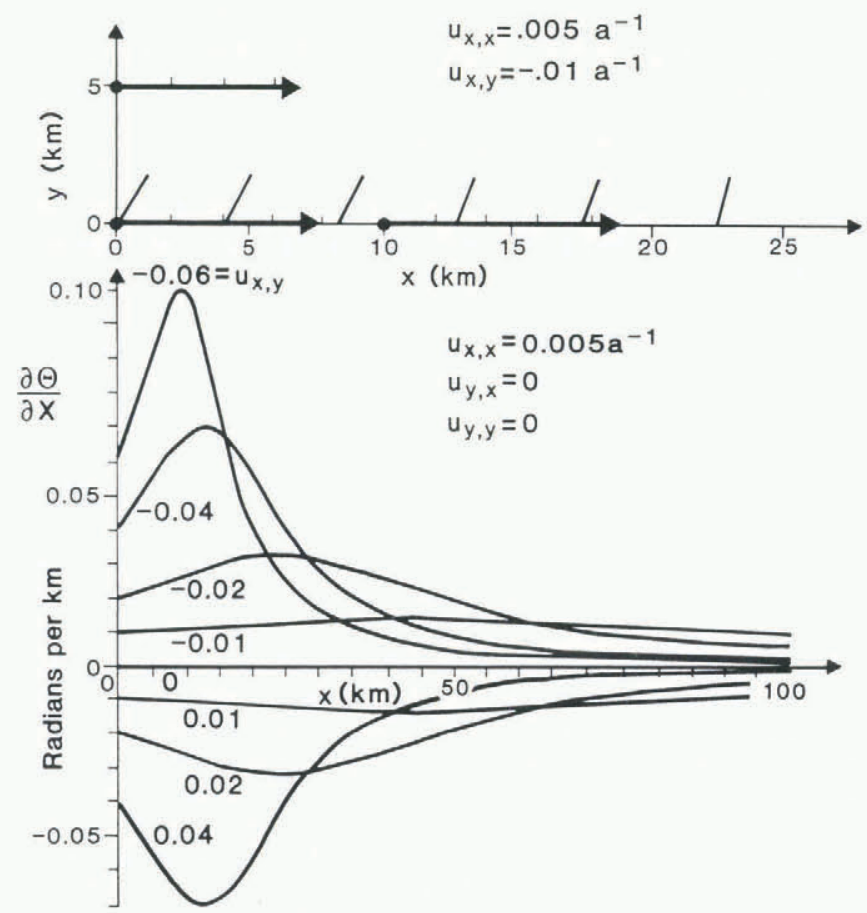

Fig. 12. Top: crevasse orientation as a function of travel distance for transverse crevasses due to simple shear, $u_{x, y}$. Short lines represent the crevasse, plotted at 10 year intervals. Heavy arrows are three velocity vectors with upward ticks at $100 \mathrm{~m} \mathrm{a}^{-1}$ to indicate scale. Bottom: crevasse turning rate versus distance for the values of $u_{x, y}$, as indicated in $a^{-1}$.

in which $u_{x}^{*}$ is the value of $u_{x}$ at the place where $\partial \theta / \partial X(\max )$ occurs. Crevasses which are oriented perpendicularly to the $x$-axis undergo the fastest turning, and those parallel to the $x$-axis undergo no turning, and for some velocity fields, there is no maximum.

Lateral extension or compression $\left(u_{y, y}\right)$ affects the initial crevasse orientation but has no effect on the value of $\partial \theta / \partial X(\max )$.

Equation (9) has been applied to Ice Stream B to estimate lateral shearing, $u_{x, y}$, using the maximum rate of change in crevasse orientation. (Flow-line turning, $u_{y, x}$, is obtained from the change in direction of crevasse bands, and is small.) There are, however, practical limitations to the application of the theory.

The main problem is, again, measurement uncertainty. The crevasses are not truly straight. Instead, they are stepped and kinked, and some are slightly curved. This leads to an uncertainty in crevasse orientation of about 0.01 rad and, for Ice Stream B, the crevasse rotation is within this measurement limitation. This leads to the conclusion that $\left|u_{x, y}\right|$ in the center of the ice stream must be less than $0.002 \mathrm{a}^{-1}$. This is not a helpful conclusion because we already know, from the absence of diagonal crevasses, that this velocity gradient is very much smaller than twice the critical strain-rate $\left(0.002 \mathrm{a}^{-1}\right)$.

The initial orientation and initial value for crevasse turning rate could be helpful. This, however, requires correctly identifying the nascent area for the crevasse band, which, because small crevasses are obscured by drifted snow, cannot be done with confidence.

The crevasse bands, however, seem to be indicators of flow-line turning, $u_{y, x}$. Crevasses in the band remain perpendicular to these flow lines, indicating that, within measurement error, the crevasse turning is the same as the flow-line turning. This flow-line turning agrees with that inferred from the orientation of the ice-stream margins and indicated by direct velocity measurement.

\section{CONCLUSIONS}

The model accounts for the observed curved marginal crevasses. Uncertainties in measuring the radius of curvature of the crevasses lead to a range of 4 in values of side shearing, which is an acceptable uncertainty for reconnaissance studies. The estimate agrees with direct measurement.

The model also accounts for the splaying crevasses at the lower end of the ice stream. Observations are satisfactorily simulated with uniform lateral extension, and side shearing varying approximately as the cube of distance from the line of symmetry of the crevasse pattern. This pattern is as expected for a simple, ice-shelf-style stress distribution and a third-power constitutive relation. The rate of side shearing needed to reproduce the pattern compares reasonably well with direct measurements.

As a final example, the model is applied to transverse crevasses in the main body of the ice stream. Theory shows that the initial and maximum values of crevasse turning rate are related to the side-shearing rate and flow-line turning. However, for Ice Stream B, the crevasses are bent and stepped, and the overall change in orientation of crevasses is less than these short-scale orientation variations along a single crevasse. Because of this, meaningful measurements for calculating side shearing cannot be made.

Changes in crevasse spacing are linked to the stretching rate. But, here too, local variability exceeds any general pattern, and measurements of crevasse spacing are not useful.

Except for the problem of local variability, the crevasse model seems to work well. The model is based on the assumptions of steady flow, linearly varying velocity field, and that there exists a critical strain-rate for crevasse formation. None of these assumptions has been fully tested and it is possible that other models may account for the observed crevasses. For example, geologists model sigmoidal extension gashes similar to our marginal crevasses using a non-steady model (e.g. Wilson, 1982, fig. 5.3; Ramsay and Huber, 1983, fig. 2.13). However, the ease with which the present model simulates the observed crevasse patterns is encouraging and suggests that the underlying assumptions are not unreasonable.

The major practical limitation is due to the local irregularity in crevasse spacing and shape. This is especially true of transverse crevasses, whose irregular spacing suggests an unsteady process of formation, irregular ice flow, or irregular ice strength. The variations in orientation along single crevasses may be due to local inhomogeneities in ice strength when the crevasse formed or to stress distortions near the tip of the growing crevasse due to its own growth or the effect of a neighboring crevasse. These local variations mean that regional trends, as used in this work, contain important measurement uncertainties.

Despite this practical limitation, the study of crevasse patterns seems to have great potential. The method may be particularly valuable in reconnaissance studies of outlet glaciers and ice streams in Antarctica and Greenland for which only satellite images are available. One might use balance velocities together with the crevasse pattern to infer the transverse variation in velocity and the relative role of side drag. That result could be important in assessing whether the glacier is decoupled from its bed and for recognizing unusual flow styles.

\section{ACKNOWLEDGEMENTS}

We thank M. Bjornerud, J. Bolzan, D. Dahl-Jensen, C. Ritz, and C.J. van der Veen for reviewing the manuscript. This project was supported by U.S. National Science Foundation grant DPP-8517590. Drafting is by R. Tope, photography is by B. Daye, and the typing is by J. Fortner and C. Gribbon. This is Byrd Polar Research Center contribution number 690 .

\section{REFERENCES}

Bindschadler, R.A., S.N. Stephenson, D.R. MacAyeal, and S. Shabtaie. 1986. Interaction between Ice Stream B and Ross Ice Shelf, Antarctica. Antarct. J. U.S., 21(5), 113-115.

Bindschadler, R.A., S.N. Stephenson, D.R. MacAyeal, and S. Shabtaie. 1987a. Ice dynamics at the mouth of Ice Stream B, Antarctica. J. Geophys. Res., 92(B9), 8885-8894.

Bindschadler, R.A., D.R. MacAyeal, and S.N. Stephenson. 1987b. Ice stream-ice shelf interaction in West Antarctica. 
In Van der Veen, C.J. and J. Oerlemans, eds. Dynamics of the West Antarctic ice sheet. Dordrecht, etc., D. Reidel Publishing Company, 161-180.

Holdsworth, G. 1965. An examination and analysis of the formation of transverse crevasses, Kaskawulsh Glacier, Yukon Territory, Canada. Ohio State Univ. Inst. Polar Stud. Rep. 16.

Holdsworth, G. 1969. Primary transverse crevasses. $J$. Glaciol., 8(52), 107-129.

Hooke, R.LeB, 1981. Flow law for polycrystalline ice in glaciers: comparison of theoretical predictions, laboratory data, and field measurements. Rev. Geophys. Space Phys., 19(4), 664-672.

Meier, M.F. 1958. The mechanics of crevasse formation. International Association of Scientific Hydrology Publication 46 (General Assembly of Toronto 1957 - Snow and Ice), 500-508.

Meier, M.F., J.E. Conel, J.A. Hoerni, W.G. Melbourne, C.J. Pings, $j r$, and P.T. Walker. 1957. Preliminary study of crevasse formation, Blue Ice Valley, Greenland, 1955. SIPRE Rep. 38.

Nye, J.F. 1952. The mechanics of glacier flow. J. Glaciol., 2(12), 82-93.

Ramsay, J.G. and M.I. Huber. 1983. Techniques of modern structural geology. Vol. 1. Strain analysis. London, etc., Academic Press.

Robin, G. de Q., C.W.M. Swithinbank, and B.M.E. Smith. 1970. Radio echo exploration of the Antarctic ice sheet. International Association of Scientific Hydrology Publication 86 (ISAGE), 97-115.

Sharp, R.P. 1960. Glaciers. Eugene, OR, Oregon State System of Higher Education.

Spiegel, M.R. 1968. Mathematical handbook of formulas and tables. New York, McGraw-Hill.

Vornberger, P.L. Unpublished. Crevasse patterns on Ice Stream B. (Thesis, Ohio State University, 1986.)

Vornberger, P.L. and I.M. Whillans. 1986. Surface features of Ice Stream B, Marie Byrd Land, West Antarctica. Ann. Glaciol., 8, 168-170.

Whillans, I.M., J. Bolzan, and S. Shabtaie. 1987. Velocity of ice streams B and C, Antarctica. J. Geophys. Res., 92(B9), 8895-8902.

Wilson, G. 1982. Introduction to small-scale geologic structures. London and Boston, Allen and Unwin.

\section{APPENDIX}

\section{DERIVATON OF PARTICLE TRAJECTORIES}

Equations (1) and (2) are rewritten as

$$
\begin{aligned}
& \left(\mathrm{d} / \mathrm{d} t-u_{x, x}\right) x-\left(u_{x, y}\right) y-u_{x}(0,0)=0 \\
& -\left(u_{y, x}\right) x+\left(\mathrm{d} / \mathrm{d} t-u_{y, y}\right) y-u_{y}(0,0)=0
\end{aligned}
$$

where $t$ represents time. These simultaneous equations are solved for the trajectory of the particle $[x(t), y(t)]$.

Solving for $y$ by eliminating $x$ from Equations (A1) and (A2), and recognizing that $u_{y}(0,0)$ is constant, leaves

$$
\begin{aligned}
& \mathrm{d}^{2} y / \mathrm{d} t^{2}-\left[u_{x, x}+u_{y, y}\right] \mathrm{d} y / \mathrm{d} t+\left[u_{x, x} u_{y, y}-u_{x, y} u_{y, x}\right] y \\
& =\left[u_{y, x^{u}}(0,0)-u_{x, x^{u}} u_{y}(0,0)\right] .
\end{aligned}
$$

This is a linear, non-homogeneous, second-order equation of the form

$$
\mathrm{d}^{2} y / \mathrm{d} t^{2}+a \mathrm{~d} y / \mathrm{d} t+b y=S
$$

with $a$ and $b$ constants. It describes the $y$-position of the particle as a function of time, and has the solution (Spiegel, 1968)

$$
\begin{gathered}
y=f \mathrm{e}^{m t}+g \mathrm{e}^{n t}+\left\{\mathrm{e}^{m t} /(m-n)\right\} \int \mathrm{e}^{-m t} S \mathrm{~d} t+ \\
+\left\{\mathrm{e}^{n t} /(n-m)\right\} \int \mathrm{e}^{-n t} S \mathrm{~d} t
\end{gathered}
$$

in which $m$ and $n$ are the roots of $M^{2}+a M+b=0$, and $f$ and $g$ are constants to be determined using boundary conditions. As applied here, $S$ is also constant, and that allows direct integration of the final terms in Equation (A4).

This solution applies if $m$ and $n$ are real and distinct. Other solutions apply when $m$ and $n$ are complex numbers. Additional special cases arise if some of the velocity gradients are zero and make the denominator of the expression for $m$ or $n$ zero. In the latter cases, zero is substituted for the appropriate velocity gradients in Equation (A3), and a special solution is obtained. All these different solutions arise in the application to Ice Stream B (Vornberger, unpublished). Here, only the derivation of the most straightforward solution is presented, but the others are similarly derived.

Substituting for $S$ in Equation (A4) and completing the integrations gives:

$$
y=f \mathrm{e}^{m t}+g \mathrm{e}^{n t}+\left[u_{y, x^{u}}(0,0)-u_{x}, x^{u} y^{(0,0)] /[m n]} .\right.
$$

$$
\begin{aligned}
& \text { with } m, n=\left\{\left[u_{x, x}+u_{y, y}\right]\right. \\
& \left.\qquad \pm\left[\left(u_{x, x}+u_{y, y}\right)^{2}-4\left(u_{x, x} u_{y, y}-u_{x, y} u_{y, x}\right)\right]^{1 / 2}\right\} / 2 .
\end{aligned}
$$

Substituting the first boundary condition (3) into Equation (A5) provides:

$$
f=y_{0}-g-\left[u_{y, x_{x}}(0,0)-u_{x, x^{u}}(0,0)\right] /[m n]
$$

and the second boundary condition (4) yields:

$$
u_{y}(0,0)+u_{y, x^{x}}+u_{y, y} y_{0}=m f+n g .
$$

Eliminating $f$ from Equations (A6) and (A7) results in

$$
\begin{aligned}
& g=\left\{u_{y}(0,0)+u_{y, x^{x}}+u_{y, y_{0}}-m y_{0}+\right. \\
& \left.+\left[u_{y, x} u_{x}(0,0)-u_{x, x^{u}} u_{y}(0,0)\right] / n\right\} /\{n-m\}
\end{aligned}
$$

and the remaining constant, $f$, is found using Equation (A6).

The equation for the $x$-position of a particle as a function of time is most simply derived in a similar manner, beginning by solving for $x$ by eliminating $y$ from Equations (A1) and (A2). 